Voix et Images

volxetimages

\title{
Lionel Groulx, mesures d'une oeuvre littéraire. Présentation
}

\section{Pierre Hébert}

Volume 19, numéro 1 (55), automne 1993

Lionel Groulx écrivain

URI : https://id.erudit.org/iderudit/201066ar

DOI : https://doi.org/10.7202/201066ar

Aller au sommaire du numéro

Éditeur(s)

Université du Québec à Montréal

ISSN

0318-9201 (imprimé)

1705-933X (numérique)

Découvrir la revue

Citer ce document

Hébert, P. (1993). Lionel Groulx, mesures d'une oeuvre littéraire. Présentation.

Voix et Images, 19(1), 8-10. https://doi.org/10.7202/201066ar d'utilisation que vous pouvez consulter en ligne.

https://apropos.erudit.org/fr/usagers/politique-dutilisation/ 


\title{
Lionel Groulx, mesures d'une œuvre littéraire. Présentation
}

\author{
Pierre Hébert, Université de Sherbrooke
}

Jean Marcel a dit de Groulx qu'il était "notre maître de prose"; Guy Frégault, "le plus professionnel de nos écrivains". De fait, peu de polygraphes ont fréquenté et maîtrisé une telle variété de discours: historiographie, roman, journal intime, souvenirs, mémoires, essai et même poésie.

Giselle-Huot ${ }^{1}$, dans son introduction au premier tome de la correspondance, dresse le bilan suivant de l'œuvre entière de Groulx: 31 ouvrages touchant l'histoire, la littérature intime et la fiction en 40 volumes, qui ont entraîné 56 rééditions et réimpressions; 55 brochures et 11 ouvrages en collaboration. Cet ensemble totalise quelque 11500 pages imprimées pour les seules éditions originales. Ajoutons à cela plus de 200 articles de revues et de journaux, plusieurs écrits divers et, bien sûr, une correspondance de 3425 lettres, entretenue avec 3737 correspondants.

L'œuvre littéraire proprement dite, on le sait, ce sont des souvenirs (Les Rapaillages, 1916), deux romans (L'Appel de la race, 1922; Au cap Blomidon, 1932), un journal intime (2 tomes), des mémoires. ( 4 tomes) et, bien sûr, la correspondance, dont la publication est actuellement en cours.

Ces ouvrages ont par ailleurs connu le plus souvent une excellente diffusion: Les Rapaillages ont dépassé 60000 mille exemplaires; L'Appel de la race a franchi le cap du $20^{\mathrm{e}}$ mille. Ce roman et $A u$ cap Blomidon sont aussi parus en bandes dessinées. Quant aux quatre tomes des mémoires, ils offrent un parcours unique de notre siècle. Enfin, la correspondance de Groulx, lorsqu'elle sera entièrement publiée, rassemblera au moins 12 volumes.

1. Giselle Huot est cosignatairè, ävec Réjean Bergeron, de l'édition critique du Journal de Groulx; elle est actuellement directrice du vaste projet d'édition critique de sa correspondance. 
Coïncidence - mais sans doute inspirée par l'ascendant de l'auteur lui-même - tous les participants à ce numéro ont ressenti la nécessité de mesurer, chacun à sa manière, le volet littéraire de cette œuvre, le plus souvent autour de la notion d'influence. Cela explique, entre autres, pourquoi l'accent est mis ici sur les ouvrages qui ont connu une large diffusion; néanmoins, l'ampleur du journal, des mémoires et de la correspondance de Groulx justifierait facilement une suite autonome au présent bloc' d'articles.

Les études du numéro suivent, dans leur ordre de présentation, l'importance généralement reconnue des ouvres: L'Appel de la race, Les Rapaillages et $A u$ cap Blomidon. L'analyse d'un corpus de dédicaces, pour clore le dossier, propose une autre saisie de la notion d'influence.

"Vaut-il la peine de rouvrir L'Appel de la race? " ̀̀ cette question qu'il pose d'entrée de jeu, Dominique Garand répond sans hésiter par l'affirmative, à la condition de ne pas considérer ce roman simplement comme un texte à défendre ou à rejeter, mais "à prendre en charge dans ses signifiants ". À l'aide de deux concepts, le polémique et l'agonique, Dominique Garand scrute attentivement le célèbre roman de Groulx: "En élucider la forme, c'est passer à la critique d'un héritage, d'une parole, d'une douleur qui continuent de travailler les sujets de parole québécois. "Cette démarche elle aussi est une réflexion sur une influence ou, à tout le moins, la mesure d'un retentissement.

Dans la seconde étude, il m'est apparu important de cerner "l'influence d'un livre", en l'occurrence le premier ouvrage littéraire de Groulx, Les Rapaillages. On a beaucoup commenté ces souvenirs, mais les circonstances qui ont entouré sa production et sa réception méritaient également d'être éclairées. Suivre la carrière des Rapaillages, c'est pratiquement refaire l'histoire du livre au Québec, particulièrement sur le plan de la succession des éditeurs qui l'ont publié; mais c'est aussi s'interroger sur une réception qui a toujours été favorable, quelle que soit l'époque visée.

Avec l'article de Stéphane Stapinsky, la notion d'influence est inversée. La critique a souvent noté, voire reproché à Groulx d'avoir inséré dans son roman $A u$ cap Blomidon un matériel historique trop abondant. Stéphane Stapinsky apporte des lumières précises sur la documentation historique utilisée par Groulx, en particulier La Tragédie d'un peuple, d'Émile Lauvrière. Cette étude permet ainsi " de considérer le documentaire historique mobilisé par Groulx au moment de la rédaction de son roman et, à partir d'exemples précis, les transformations qu'il lui a fait subir". 
Enfin, Jean-Pierre Chalifoux et moi-même proposons une étude sur les dédicaces qui accompagnent les ouvrages offerts à Lionel Groulx. La dédicace d'exemplaire fournit un matériau très riche pour cerner les liens réciproques entre dédicateurs et dédicataire; mais le plus souvent, la difficulté tient à la constitution du corpus. Le cas de Groulx est cependant remarquable puisque, des 8000 volumes et brochures de sa bibliothèque, 712 lui ont été dédicacés. Ce corpus nous permet d'analyser les formes de la dédicace, les caractéristiques de cet ensemble et, enfin, de dresser le profil des partenaires de cet échange.

Comment, pour terminer cette présentation, feindre d'ignorer le contexte où paraît ce numéro? Une polémique perdure, on le sait, depuis l'automne 1991, sur le racisme, le fascisme de Groulx. Dans l'état actuel d'un discours social fortement polarisé, la neutralité, même proclamée, est sans doute impossible. J'insiste pourtant sur l'origine du présent numéro: à une réunion du comité de rédaction de Voix et Images du 7 juin 1991, je proposais pour la première fois cette idée. J'ajouterai; dans une petite note personnelle qui n'intéressera peut-être personne, que l'étymologie lointaine de ce numéro prolonge ses racines dans cet étonnement (était-ce même de l'émerveillement à l'époque?) que j'ai ressenti lorsque, jeune étudiant, je suis entré en contact avec la monumentalité de l'œuvre de Groulx. Depuis vingt ans, j'ai interrogé sporadiquement certains de ses textes; mais j'ai surtout voulu susciter ici l'occasion d'une réflexion plus large, plus variée où se rencontrent les discours d'un historien, d'un bibliothécaire et, bien sûr, de littéraires, autour d'une nouvelle appréciation de cette œuvre. 